\title{
On the protective mechanisms of nitric oxide in acute pancreatitis
}

\author{
J Werner, C Fernández-del Castillo, J A Rivera, N Kollias, K B Lewandrowski, \\ D W Rattner, A L Warshaw
}

\begin{abstract}
Background-Ectopic protease activation, microcirculatory changes, and leucocyte activation are the main events in the pathogenesis of acute pancreatitis. Nitric oxide (NO) is known to be a key mediator in the normal and inflamed pancreas.

Aims-To investigate the targets on which NO exerts its effect in caerulein induced pancreatitis.

Methods-Acute pancreatitis was induced in rats which additionally received either the NO synthase substrate, L-arginine; the NO donor, sodium nitroprusside; or the NO synthase inhibitor, $N$-nitro-L-arginine methyl ester (L-NAME). At six hours, pancreatic injury (oedema, leucocyte content, ectopic trypsinogen activation) was analysed and pancreatic oxygenation and perfusion were determined. A direct influence of NO on amylase secretion and trypsinogen activation was evaluated separately in vitro.
\end{abstract}

Results-Both NO donors reduced the grade of inflammation. L-NAME increased the severity of inflammation, while decreasing pancreatic tissue oxygenation. Although neither amylase secretion nor intracellular trypsinogen activation in caerulein stimulated pancreatic acini was influenced by either NO donors or inhibitors, both NO donors decreased intrapancreatic trypsinogen activation peptide (TAP) and pancreatic oedema in vivo, and L-NAME increased TAP.

Conclusions-NO protects against injury caused by pancreatitis in the intact animal but has no discernible effect on isolated acini. It is likely that in pancreatitis NO acts indirectly via microcirculatory changes, including inhibition of leucocyte activation and preservation of capillary perfusion.

(Gut 1998;43:401-407)

Keywords: acute pancreatitis; nitric oxide; microcirculation; leucocytes; pancreatic secretion

Nitric oxide (NO) has recently emerged as a biological regulatory substance in a variety of cell types including endothelium, ${ }^{1}$ macrophages, ${ }^{2}$ platelets, ${ }^{3}$ and the pancreas, ${ }^{4}$ in which $\mathrm{NO}$ is synthesised from L-arginine by constitutive enzymes. ${ }^{5}$ Its physiological actions are mainly mediated by cyclic guanosine monophosphate (cGMP). ${ }^{6}$ In the pancreas, intra- cellular cGMP concentrations increase in response to certain secretagogues, such as cholecystokinin, ${ }^{5}$ and $\mathrm{NO}$ thereby plays an active role in pancreatic secretion. ${ }^{78}$ Outside the pancreatic cells NO plays a part in the control of systemic blood pressure and active dilatation of blood vessels, ${ }^{910}$ and is additionally involved in platelet aggregation, ${ }^{11}$ leucocyte activation, and adhesion. ${ }^{12-14}$

Central events in the pathogenesis of acute pancreatitis are microcirculatory changes, ${ }^{15} 16$ leucocyte dependent inflammatory processes, ${ }^{17} 18$ and premature or ectopic pancreatic protease activation. ${ }^{192}$ It has recently been shown that NO has a beneficial effect on certain features of acute pancreatitis, both mild and severe. ${ }^{21-23}$ We found that NO donors decrease pancreatic oedema formation, intrapancreatic trypsinogen activation, and amylase secretion. ${ }^{21}$ These experiments did not elucidate the mechanism or site of activation of NO in pancreatitis, but the beneficial effect of inhaled $\mathrm{NO}^{21}$ suggested a target in addition to the pancreatic acinar cell, possibly on leucocyte-endothelium interaction, platelet aggregation, and pancreatic perfusion. In the present study we utilised reflectance spectroscopy to evaluate in vivo the effects of NO donors and antagonists on pancreatic oxygenation in caerulein induced pancreatitis, quantitated pancreatic leucocyte infiltration by histological scoring and assay of myeloperoxidase activity, and in addition measured the conventional indexes of pancreatic injury (oedema, blood amylase levels, and ectopic trypsinogen activation). Some effects of $\mathrm{NO}$ on isolated acini were compared with its effects in the intact animal.

\section{Materials and methods \\ IN VIVO STUDIES}

Animals

Experiments were performed in male SpragueDawley rats weighing 275-325 g. Animals were fasted overnight prior to the experiment with free access to water. Care was provided in accordance with the procedure outlined in the Guide for Care and Use of Laboratory Animals (NIH Publication 85-23, 1985). Surgical anaesthesia was induced with vaporised ether and maintained by an intramuscular injection of pentobarbital $(20 \mathrm{mg} / \mathrm{kg})$ and ketamine (40 $\mathrm{mg} / \mathrm{kg})$. Polyethylene catheters $(0.5 \mathrm{~mm}$ internal diameter) were inserted into the right jugular vein and the left carotid artery, subcutaneously tunnelled to the back, and exited through a steel tether that allowed the animals free movement and access to water during the experiment. 
Model

Animals were allocated to the control group $(n=20)$, which received intra-arterial saline, or to the acute pancreatitis group $(n=80)$; acute pancreatitis was induced by continuous intraarterial infusion of caerulein $(5 \mu \mathrm{g} / \mathrm{kg} / \mathrm{h})$ for six hours. ${ }^{24}$ Caerulein was reconstituted in normal saline and infused at $3 \mathrm{ml} / \mathrm{kg} / \mathrm{h}$.

Nitric oxide donors or inhibitors were administered simultaneously with caerulein in 60 animals of the pancreatitis group. The nitric oxide synthase substrate L-arginine $(25 \mathrm{mg} / \mathrm{kg}$ bolus and subsequently $5 \mathrm{mg} / \mathrm{kg} / \mathrm{h}),{ }^{1}$ the exogenous NO donor sodium nitroprusside (SNP, $0.2 \mathrm{mg} / \mathrm{kg} / \mathrm{h}),{ }^{25}$ and the NO synthase inhibitor N-nitro-L-arginine methyl ester (L-NAME, 10 $\mathrm{mg} / \mathrm{kg}$ bolus and subsequently $2.5 \mathrm{mg} / \mathrm{kg} / \mathrm{h})^{26}$ were infused intravenously over six hours in 20 animals of each subgroup.

At six hours, end point measurements of heart rate (HR), mean arterial pressure (MAP), amylase, and trypsinogen activation peptide (TAP) in serum were obtained. Ten animals of each subgroup were then sacrificed by an intra-arterial pentobarbital overdose $(200 \mathrm{mg} / \mathrm{kg})$, and the pancreas was assessed for oedema formation, ectopic trypsinogen activation, myeloperoxidase activity, and histology. In the remaining 10 animals reflectance spectroscopy of the pancreas was performed as described below.

\section{Monitoring}

MAP and HR were monitored by a thermal recorder (Mark 10-1; Western Graphetec, Irvine, California). Measurements of amylase and TAP in serum were obtained before the induction of pancreatitis (baseline) and after six hours (end point). The blood volume of each sample was replaced with double the amount of Ringer's lactate.

\section{Reflectance spectroscopy}

In a separate set of experiments designed to evaluate end points of tissue oxygenation and oxygen consumption, pancreatic haemoglobin content and oxygen saturation of haemoglobin $\left(\mathrm{ISO}_{2}\right)$ were measured using diffuse reflectance spectroscopy as previously described. ${ }^{1627}$ Briefly, the abdomen was opened, and a probe head ( $2.5 \mathrm{~mm}$ diameter) of a modified diode array spectrophotometer (HP 84523, Hewlett Packard, California) emitting and receiving light was placed on the pancreatic surface. Spectral changes in the reflected light were analysed by a connected personal computer (Vectra CS, Hewlett Packard, California); $\mathrm{ISO}_{2}$ was calculated from the absorbance at $577 \mathrm{~nm}$ (absorbance maximum of oxygenated haemoglobin) and $555 \mathrm{~nm}$ (absorbance maximum of deoxygenated haemoglobin), plotted against pancreatic haemoglobin content, determined from the absorbance at the isobestic point ( 586 $\mathrm{nm})$. Measurements were performed in 10 animals per group at five selected sites in the duodenal portion of the gland at baseline and at the end point after six hours. Data are expressed as mean (SEM) of the difference of oxyhaemoglobin or deoxyhaemoglobin content in pan- creatic tissue between baseline and end point at six hours.

\section{Myeloperoxidase activity}

Excised pancreatic tissues were rinsed with saline, blotted dry, shock frozen in liquid nitrogen, and stored frozen at $-80^{\circ} \mathrm{C}$ until thawing for determination of myeloperoxidase activity using methods previously described ${ }^{28-30}$ with minor modifications. Pancreatic tissue was homogenised in $0.1 \mathrm{M}$ sodium phosphate buffer containing $0.5 \%$ hexadecyl trimethyl ammonium bromide (Sigma H5882, Sigma Chemical Co.) and 5\% soybean trypsin inhibitor (Sigma T9003, Sigma Chemical Co.) before sonication and was then frozen directly on dry ice. The specimens were freeze thawed three times, and after each cycle sonication was repeated. Suspensions were then centrifuged at $20000 \mathrm{~g}$ for 15 minutes and the resulting supernatant assayed. Myeloperoxidase activity was measured with a spectrophotometer (Shimazdu, UV-160, Japan) at $470 \mathrm{~nm}$ by mixing an aliquot $(25 \mu \mathrm{l})$ of the supernatant with 1.0 $\mathrm{ml}$ of $0.1 \mathrm{M}$ sodium phosphate buffer ( $\mathrm{pH} 7.0$ ) containing $0.0016 \mathrm{ml}$ guaiacol (Sigma G-5502, Sigma Chemical Co.) and $0.0005 \%$ hydrogen peroxide (Sigma T9003, Sigma Chemical Co.) as substrates.

\section{Histological assessment}

The duodenal portion of the pancreas was fixed in $10 \%$ buffered formalin, embedded in paraffin wax, and one longitudinal section stained with haematoxylin and eosin. Histopathological evaluation was performed by one pathologist with expertise in pancreatic pathology who was blind to the experimental protocol. Morphometric documentation was obtained for acinar necrosis and inflammation, using a scoring system from 0 (no pathological changes) to 3 (maximal inflammatory infiltration, total necrosis of the panceas), as described by Schmidt et al. ${ }^{31}$

\section{Oedema assessment}

Pancreatic oedema was evaluated by measuring water content. A portion of the pancreas was removed immediately after sacrifice, trimmed of fat, and weighed. Pancreatic water content was determined by calculating the wet:dry weight ratio from the initial weight of the pancreas (wet weight) and its weight after incubation at $160^{\circ} \mathrm{C}$ for 24 hours (dry weight) as described previously. ${ }^{21}$

\section{Trypsinogen activation peptide measurements}

Ectopic trypsinogen activation has been shown within the pancreas in a variety of models of experimental pancreatic injury. ${ }^{202130}$ The amount of activation, as documented by quantitation of TAP, increases with the severity of pancreatic injury ${ }^{32}$ and predicts the outcome of pancreatitis. ${ }^{19}$ For measurement of TAP concentrations in pancreatic tissue, two samples of tissue $(0.1-0.3 \mathrm{~g})$ were excised from the pancreas. The specimens were then immersed in $0.2 \mathrm{M}$ Tris- $\mathrm{HCl}$ buffer ( $\mathrm{pH}$ 7.3) containing $20 \mathrm{mM}$ EDTA, immediately boiled $\left(100^{\circ} \mathrm{C}\right)$ for 10 minutes to denature residual protease 
Table 1 Influence of nitric oxide on vital signs, pancreatic secretion and pancreatic histology in patients with pancreatitis

\begin{tabular}{|c|c|c|c|c|c|}
\hline & Control & Caerulein & $+L$-arginine & $+S N P$ & ${ }^{+} L-N A M E$ \\
\hline \multicolumn{6}{|l|}{ MAP } \\
\hline 0 hours & $124(2)$ & $128(3)$ & $121(2)$ & $126(2)$ & $124(2)$ \\
\hline 6 hours & $125(2)$ & $127(2)$ & $114(2) \dagger$ & $117(1) \dagger$ & $138(2) \dagger$ \\
\hline \multicolumn{6}{|l|}{$\mathrm{HR}$} \\
\hline 0 hours & $329(8)$ & $328(7)$ & $338(6)$ & $332(6)$ & $330(7)$ \\
\hline 6 hours & $329(6)$ & $339(7)$ & $326(7)$ & $337(6)$ & $340(6) \ddagger$ \\
\hline Amylase $(\mathrm{U} / \mathrm{l})$ & $11(4)$ & $381(35)^{\star}$ & $122(31) \dagger$ & $161(34) \dagger$ & $297(44)$ \\
\hline TAP (serum, nmol/1) & $1.43(0.44)$ & $4.19(1.04)^{\star}$ & $1.43(0.38) \dagger$ & $2.72(1.32) \dagger$ & $14.12(4.81)$ \\
\hline TAP (tissue, $\mathrm{nmol} / \mathrm{g}$ ) & $92(11)$ & $223(27)^{\star}$ & $135(22) \ddagger$ & $153(31) \ddagger$ & $398(56) \ddagger$ \\
\hline Oedema & $3.13(0.1)$ & $12.15 \pm 0.73)^{\star}$ & $5.47(0.56) \dagger$ & $6.04(0.39) \dagger$ & $8.76(0.32) \dagger$ \\
\hline Inflammation & $0.00(0.00)$ & $0.85(0.07)^{\star}$ & $0.035(0.89) \dagger$ & $0.55(0.06) \dagger$ & $1.03(0.03) \ddagger$ \\
\hline Necrosis & $0.05(0.03)$ & $0.63(0.06)^{\star}$ & $0.035(0.09) \ddagger$ & $0.58(0.05)$ & $0.56(0.04)$ \\
\hline
\end{tabular}

${ }^{\star} \mathrm{p}<0.005$ compared with control; $\nmid \mathrm{p}<0.005$ compared with caerulein; $\neq \mathrm{p}<0.05$ compared with caerulein.

activity, and homogenised with a Brinkman Polytron (Brinkman Instruments, Westbury, New York) for 30 seconds. After centrifugation $\left(580 \mathrm{~g}, 10\right.$ minutes, $4^{\circ} \mathrm{C}$ ), the resulting supernatant was stored at $-20^{\circ} \mathrm{C}$ until assayed. TAP was measured by an enzyme linked immunosorbent assay (ELISA) ${ }^{20}$ and results expressed as nmol TAP per mg pancreas. Synthetic TAP (YD4K), a conjugate of rabbit serum albumin with YD4K, and rabbit anti-

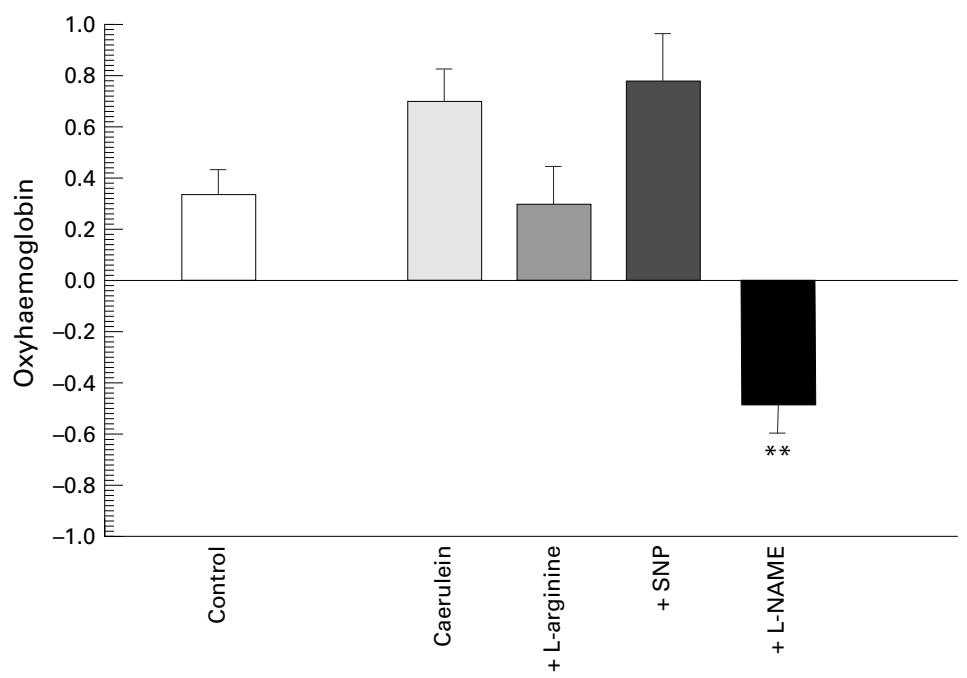

Figure 1 Diffuse reflectance spectroscopy. Difference in oxyhaemoglobin content in pancreatic tissue between baseline ( 0 hours) and end point (6 hours) measurements. $\star \star p<0.01$ compared with caerulein.

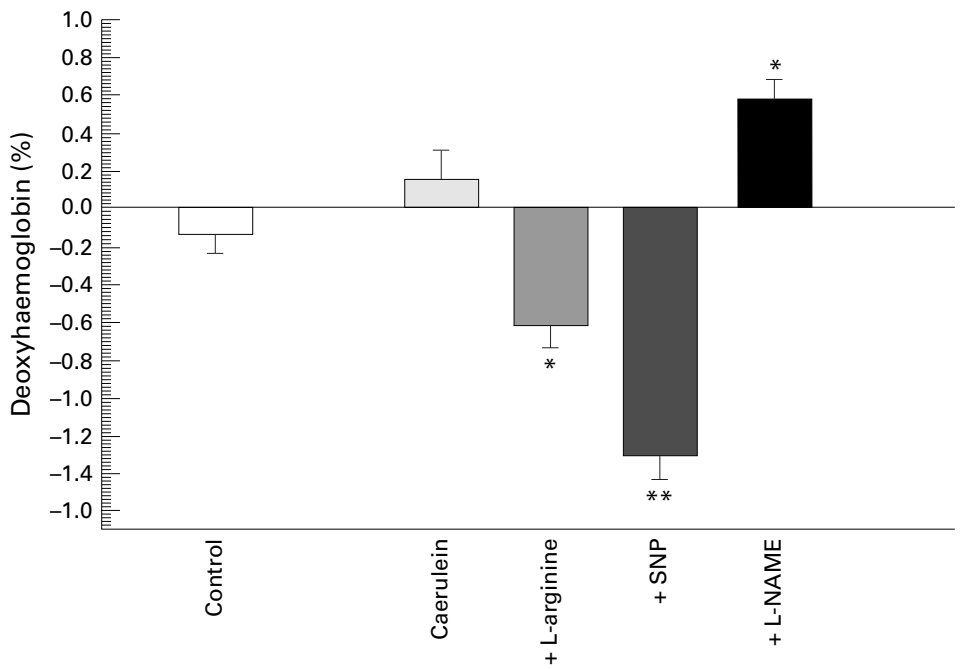

Figure 2 Diffuse reflectance spectroscopy. Difference in deoxyhaemoglobin content in pancreatic tissue between baseline (0 hours) and end point (6 hours) measurements. $\star_{p}<0.05, \star_{p}<0.01$ compared with caerulein.
TAP antiserum containing calcium independent anti-TAP antibodies were provided by Professor J Hermon-Taylor (St George's Hospital Medical School, London, UK). Biotin-goat antirabbit IgG antibody and alkaline phosphatase labelled extravadin were purchased from Sigma Chemical Company.

Amylase measurement

Amylase activity in serum was determined according to the method of Ceska $e t a l^{33}$ using the Phadebas Amylase Test (Pharmacia Diagnostics, Uppsala, Sweden).

\section{IN VITRO STUDIES}

Pancreatic acinar cell suspensions

For each experiment three male Wistar rats (80-120 g) were fasted overnight and sacrificed in $\mathrm{CO}_{2}$. The pancreas was quickly excised in a cold room and pancreatic acini prepared by collagenase (type CLS 4, $1000 \mathrm{U} / \mathrm{ml}$, Worthington Biochemical Corporation, Freehold, New Jersey) digestion as described in detail previously. ${ }^{34}$ After collagenase digestion the pancreatic cells were washed with medium containing HEPES $12.5 \mathrm{mM}, \mathrm{NaHCO}_{3} 5.0$ $\mathrm{mM}, \mathrm{NaCl} 125 \mathrm{mM}, \mathrm{KCl} 5.0 \mathrm{mM}, \mathrm{CaCl}_{2} 1.2$ $\mathrm{mM}, \mathrm{KH}_{2} \mathrm{PO}_{4} 1.2 \mathrm{mM}, \mathrm{MgSO}_{4} 1.2 \mathrm{mM}$, D-glucose $5.0 \mathrm{mM}$, aprotinin $0.01 \mathrm{mg} / \mathrm{ml}$, soybean trypsin inhibitor $0.1 \mathrm{mg} / \mathrm{ml}$, and bovine serum albumin $0.1 \%$ at a $\mathrm{pH}$ of 7.40 (all chemicals from Sigma Chemical Company). The pancreatic acinar cells were then isolated by centrifugation (three times at $100 \mathrm{~g}$ ) and filtering (polyethylene filter, mesh opening 292 $\mu \mathrm{m}$, Spectra/Mesh, Spectrum, Houston, Texas). Cell viability was tested with the trypan blue exclusion method immediately after preparation of acini by collagenase digestion. Preparations were accepted for study only if more than $95 \%$ of the cells excluded the dye.

The cells were incubated at $37^{\circ} \mathrm{C}$ in 24 well cell culture plates (Falcon 3047, Becton Dickinson Labware, Lincoln Park, New Jersey) with $500 \mu \mathrm{l}$ of cell suspension in each well, gassed with $100 \%$ oxygen. In the first study with pancreatic acinar cells, the effect of different concentrations of NO donors and inhibitors on pancreatic secretion in normal and stimulated cells was investigated. Pancreatic anini were preincubated for 15 minutes, before different dosages of L-arginine $(1,5,10,50$, and 100 $\mathrm{mmol} / \mathrm{l}), \operatorname{SNP}(1,5,10,50$, and $100 \mathrm{mmol} / \mathrm{l})$, or L-NAME $(1,5,10,50$, and $100 \mathrm{mmol} / \mathrm{l})$ were added for 30 minutes. Saline or supraphysiological stimulation with caerulein $\left(10^{-10}\right.$ 


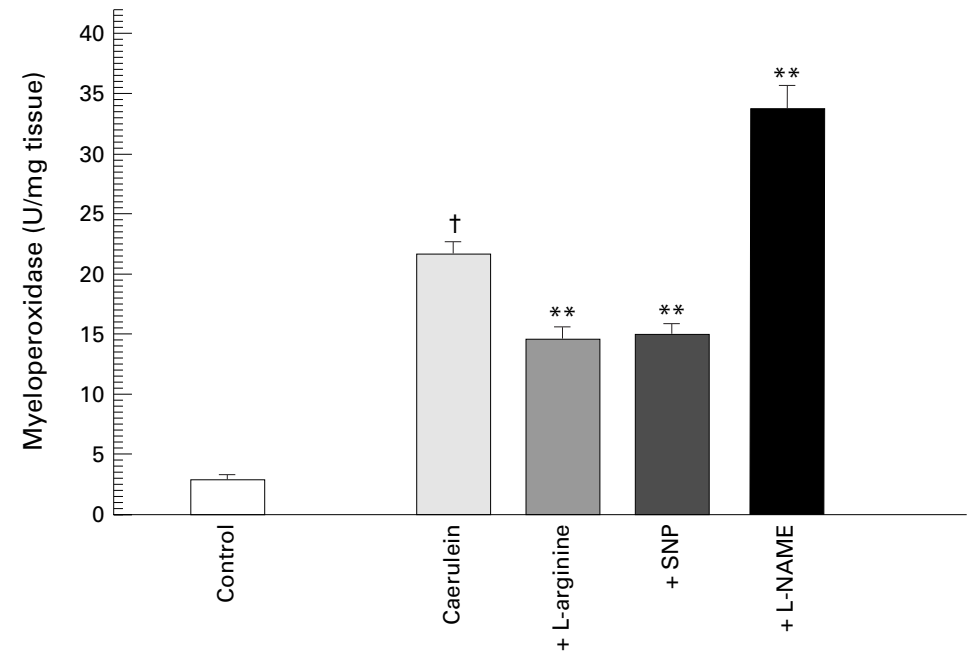

Figure 3 Leucocyte infiltration of pancreatic tissue as evaluated by myeloperoxidase activity. ${ }^{\star *} p<0.01$ compared with caerulein; $\dagger p<0.05$ compared with control.

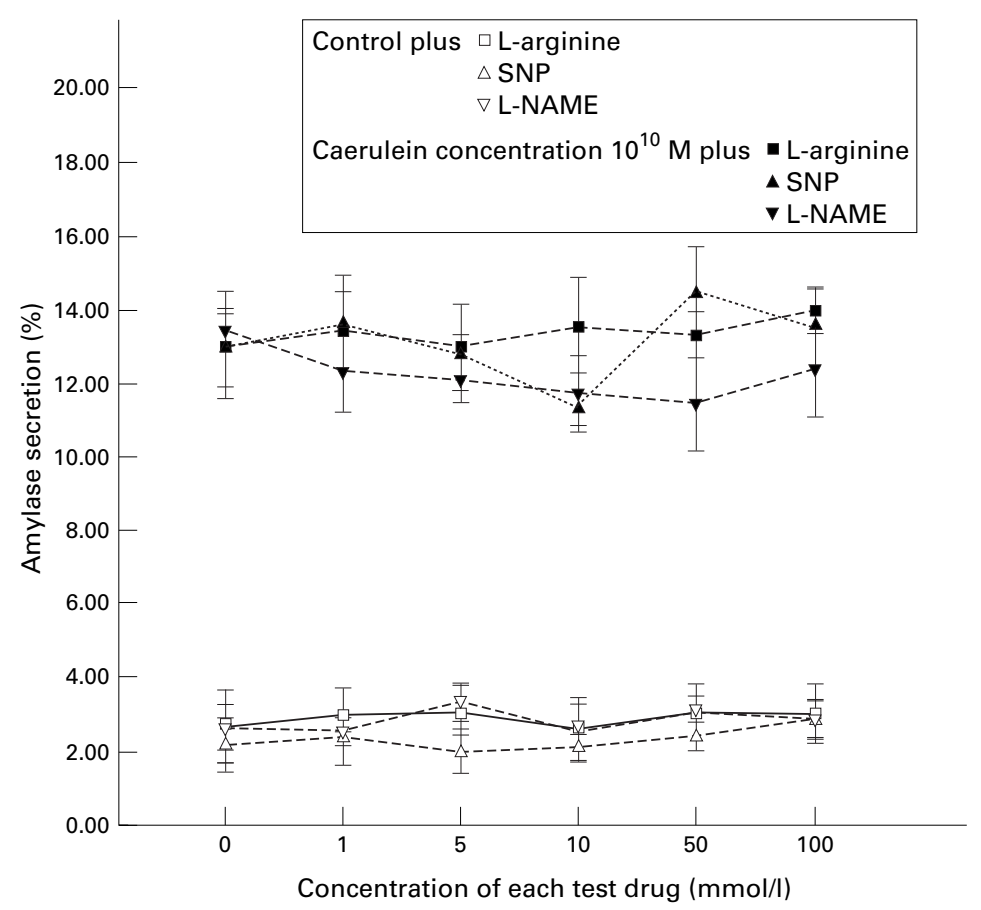

Figure 4 Influence of NO donors and inhibitors on amylase secretion of unstimulated versus secretory stimulated pancreatic acini.

$\mathrm{mmol} / \mathrm{l}$ ) was then applied for one hour. In a second series of experiments, the influence of $\mathrm{NO}$ on different grades of secretory stimulation was studied. After incubation with the NO donors L-arginine $(10 \mathrm{mmol} / \mathrm{l})$ or SNP (1 $\mathrm{mmol} / \mathrm{l})$, or the $\mathrm{NO}$ synthase inhibitor L-NAME $(10 \mathrm{mmol} / \mathrm{l})$, or with saline (control group) for 30 minutes, pancreatic acini were exposed to different concentrations of caerulein $\left(10^{-12}-10^{-8} \mathrm{mmol} / \mathrm{l}\right)$ for 60 minutes. At the end of the one hour incubation period 150 $\mu \mathrm{l}$ of the medium was removed to assay for amylase and TAP in the supernatant. All measurements were performed in duplicate, and controls were run on each plate. Then $400 \mu \mathrm{l}$ Tris (0.1 M, pH 8.9) and Triton X-100 (2\%) was added for cell homogenisation and the plates were incubated on a mini shaker for 30 minutes at room temperature; amylase (total amylase) and TAP were again assayed as described above. Finally, to ascertain the relation of the observed TAP levels to the total trypsinogen pool, the acinar cells were incubated with enterokinase $(1 \mathrm{U} / \mathrm{ml})$ for one hour at $37^{\circ} \mathrm{C}$ to convert all trypsinogen to equimolar quantities of trypsin and TAP. The added TAP (total TAP) at this last step thus represents the trypsinogen content of the cells, as opposed to the activated trypsin. TAP levels were expressed as a function of total trypsinogen to indicate the degree of activation.

\section{STATISTICAL ANALYSIS}

Results are presented as mean (SEM). Differences between groups were compared using analysis of variance followed by Student's $t$ test. When a normal distribution was not present (TAP), the non-parametric analysis of variance (Kruskal-Wallis test) was used for statistical analysis followed by the Mann-Whitney rank sum test. A 5\% probability of type I experimental error $(p<0.05)$ was considered statistically significant.

\section{Results}

IN VIVO STUDIES

There was no difference among the five subgroups at baseline with respect to MAP or HR. Six hours after induction of pancreatitis, there was still no difference in MAP or HR between control animals and those in which pancreatitis was induced without additional administration of $\mathrm{NO}$ donors or inhibitors. Based on pilot studies to determine the appropiate effective doses of NO donors and NO inhibitors, the dosages were chosen such that the MAP in animals with pancreatitis was lowered approximately $10 \mathrm{~mm} \mathrm{Hg}$ if L-arginine or SNP was administered, and raised $10 \mathrm{~mm}$ $\mathrm{Hg}$ by L-NAME (table 1). These changes in MAP indicate that the dosages were sufficient to produce an effect but small enough to be unlikely to influence the further course of pancreatitis.

\section{Reflectance spectroscopy}

Control rats maintained their oxyhaemoglobin (fig 1) and deoxyhaemoglobin (fig 2) concentrations in pancreatic tissue over the six hour observation interval, indicating stable oxygenation and presumably stable perfusion in the experimental conditions. Similarly there were no significant changes in these parameters after six hours of caerulein induced pancreatitis. The addition of L-arginine reduced the amount of deoxyhaemoglobin in the pancreatic tissue, while oxyhaemoglobin remained constant. The same was true for the addition of SNP, suggesting a relative increase effective pancreatic perfusion by the action of NO donors. In contrast, the addition of L-NAME led to a significant decrease in pancreatic oxygenation, as shown by a decreased oxyhaemoglobin content and increased deoxyhaemoglobin content (figs 1 and 2).

\section{Myeloperoxidase activity in pancreatic tissue}

Pancreatitis led to significant leucocyte accumulation of pancreatic myeloperoxidase activ- 


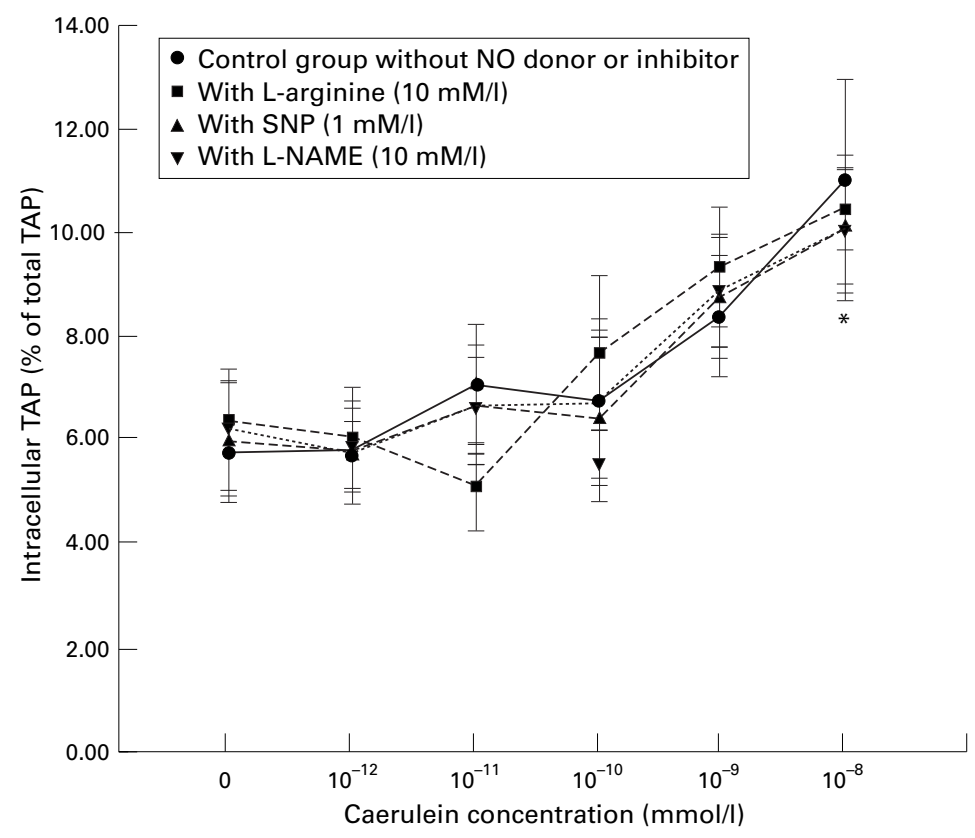

Figure 5 Influence of NO donors and inhibitors on intracellular TAP formation in pancreatic acinar cells (as a measurement of intracellular trypsinogen activation) in response to different grades of secretory stimuli with caerulein. ${ }^{\star} p<0.05$ compared with control group and with caerulein $10^{-12} \mathrm{M}$.

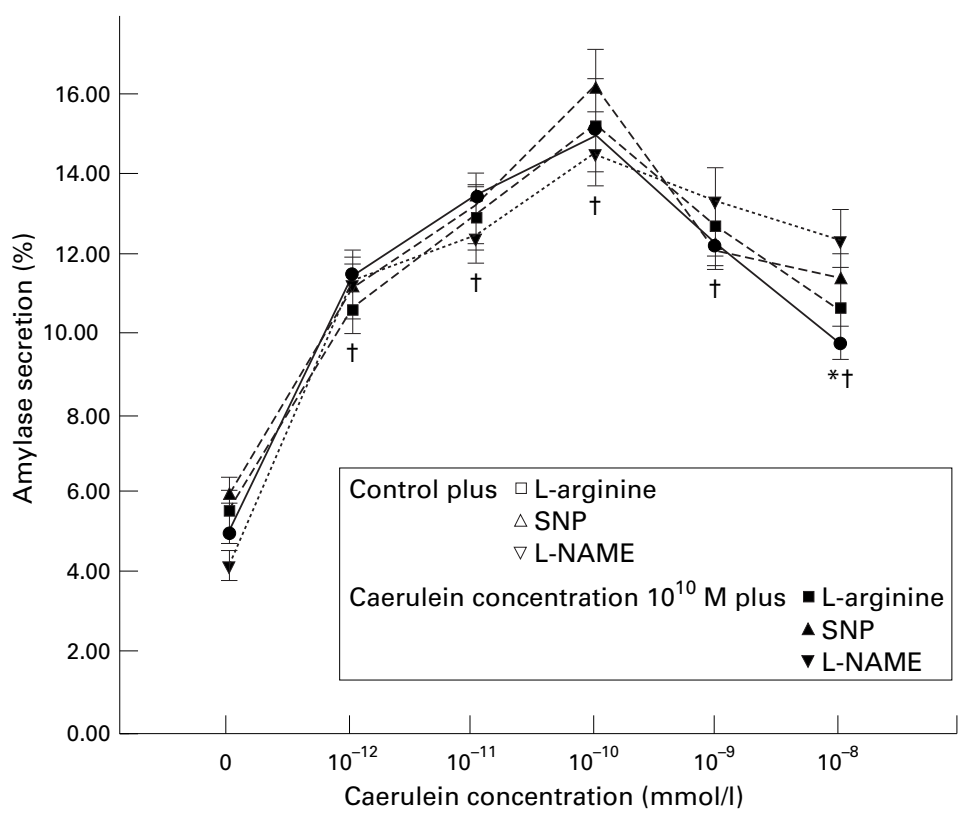

Figure 6 Influence of NO donors and inhibitors on amylase secretion by pancreatic acinar cells in response to different grades of secretory stimuli with caerulein. ${ }^{\star} p<0.05$ compared with caerulein $10^{-12} \mathrm{M} ; t p<0.05$ compared with control.

ity $(\mathrm{p}<0.001$ compared with controls), which was reduced by both L-arginine and SNP, but greatly increased by L-NAME (fig 3).

\section{Histological assessment}

Specimens of control animals (no pancreatitis) showed normal acinar architecture. Caerulein induced pancreatitis led to obvious interstitial oedema and slight inflammation but little necrosis. L-arginine decreased inflammation and necrosis significantly, and SNP had a lesser effect in the same direction. In contrast, administration of L-NAME increased the inflamma- tory response, but there was no additional necrosis detectable by six hours (table 1 ).

\section{Pancreatic oedema}

Caerulein infusion induced gross pancreatic oedema as reflected by an increase in wet:dry ratio (table 1). The NO donors L-arginine and SNP greatly decreased the water content; the NO synthase inhibitor L-NAME also reduced water content.

\section{Amylase and TAP in serum}

There was significant hyperamylasaemia in animals with pancreatitis induced by supramaximal caerulein stimulation. Compared with caerulein alone, L-arginine and SNP significantly decreased the hyperamylasaemia $(\mathrm{p}<0.001)$; L-NAME had no effect (table 1). TAP in serum (TAP at six hours minus TAP at baseline) was significantly increased in animals with pancreatitis in comparison with control animals (table 1 ). The addition of NO promoters significantly decreased TAP in serum, while the NO synthase inhibitor had no significant effect on serum TAP values compared with animals with pancreatitis.

\section{Pancreatic tissue TAP}

Caerulein induced pancreatitis increased TAP values in the pancreatic tissue homogenates significantly $(p<0.001)$. Both L-arginine and SNP reduced trypsinogen activation while L-NAME increased the tissue TAP (table 1).

IN VITRO STUDIES

Amylase secretion was notably increased when acinar cells were stimulated with a supraphysiological concentration of caerulein $\left(10^{-10}\right.$ $\mathrm{mmol} / \mathrm{l})$ compared with unstimulated cells $(p<0.001$; fig 4$)$ and intracellular trypsinogen activation was slightly increased by caerulein stimulation (fig 5). The typical biphasic shape of the caerulein dose-response curve of amylase secretion, which indicates the functional viability of the acinar cell preparation, was not altered by L-arginine (10 $\mathrm{mmol} / \mathrm{l})$, SNP (1 $\mathrm{mmol} / \mathrm{l})$, or L-NAME (10 $\mathrm{mmol} / \mathrm{l})$ (fig 6). There was no effect on amylase secretion from the addition of different concentrations of NO donors or inhibitors to either unstimulated or stimulated cells (fig 4). There was no influence of L-arginine, SNP, or L-NAME on intracellular TAP at any concentration tested (data not shown) or at any level of secretory stimulation (fig 5).

\section{Discussion}

We have previously shown that NO donors in vivo may confer some protection in acute experimental pancreatitis, both mild and severe, by reducing oedema formation, hyperamylasaemia, and ectopic trypsinogen activation and that inhibition of $\mathrm{NO}$ synthase produces the obverse deleterious effects. Other studies have been in accord, ${ }^{72} 232535$ but disagreement also exists. ${ }^{22} 36{ }^{37}$ None of these previous investigations have shed light on the mode or site of action of NO, whether it be directly on the acinar cell or indirectly mediated through microcirculatory changes or other remote 
mechanisms. In this study we analysed the influence of L-arginine, SNP, and L-NAME on the development of pancreatitis both in vivo and in vitro. At the cellular level we utilised parameters to indicate secretory function and premature intracellular protease activation, and in vivo we measured leucocyte accumulation, tissue oxygenation, and protease activation. These studies were designed to distinguish between effects of NO at the cellular level and those which are the vector of systemic actions. The present study supports our previous findings that NO plays a protective role in the evolution of acute pancreatitis in that all the measures of injury were ameliorated by the administration of L-arginine or SNP and worsened by L-NAME. The new observations of greatest importance are that $\mathrm{NO}$ donors reduce the numbers of leucocytes accumulating in the pancreas in pancreatitis and improve tissue oxyhaemoglobin concentrations, while inhibition of NO synthase is harmful to these same parameters.

Pancreatic perfusion and tissue oxygenation have been considered to be key factors in the pathogenesis and progression of pancreatitis, ${ }^{15} 16$ and the benefits of NO therefore appear to be particularly relevant. Recent reports about NO, also described as endothelium derived relaxing factor, ${ }^{10}$ describe cytoprotective effects through increase of organ blood flow in several organs including the intestine, ${ }^{38}$ liver, ${ }^{39}$ and pancreas. ${ }^{35}{ }^{40}$ Progression of pancreatitis may well be dependent on the balance between protectors of microcirculatory perfusion and those agents which serve to produce the reduction in capillary flow and perfusion which characterise severe necrotising pancreatitis. ${ }^{15} 16$ We suggest that NO plays a significant role in this balance. Our diffuse reflectance spectroscopy data show that the addition of $\mathrm{NO}$ reduces the pancreatic tissue content of deoxyhaemoglobin, while NO synthase inhibition increases deoxyhaemoglobin and diminishes oxyhaemoglobin in caerulein induced pancreatitis. In our previous studies these changes correlated with improved or impaired tissue blood flow respectively. ${ }^{1627} \mathrm{We}$ infer from the present observations that the effects of nitric oxide are mediated in part by changes in effective microcirculation.

Leucocyte adhesion to the endothelium in postcapillary venules, progressive accumulation, and infiltration into pancreatic tissue is a prominent and constant feature of all models of acute pancreatitis. ${ }^{17} 3041$ Firstly, NO is known to be a protective modulator against leucocyte adherence, ${ }^{11} 12$ and impairment of endogenous NO generation enhances leucocyte adhesion and migration into tissues. ${ }^{6}{ }^{12}$ This phenomenon is exemplified in the present study by the increased myeloperoxidase activity in animals treated with L-NAME and by the complementary finding of decreased myeloperoxidase produced by L-arginine and SNP. Leucocytes may initiate or potentiate cell damage by several mechanisms, including free oxygen radical and cytokine production. ${ }^{42}$ Hypoxic tissue and leucocytes are the two principal sources of free radicals which are generated early in the course of pancreatitis and lead to exacerbation of pancreatic cell injury. ${ }^{43}$ Secondly, NO functions as a superoxide scavenger and reduces superoxide anion production in neutrophils. ${ }^{14}{ }^{44}$ Finally, $\mathrm{NO}$ is thought to maintain vascular integrity in the leucocyte independent early increase in microvascular permeability as well as in the delayed vascular dysfunction that is probably mediated by toxic secretions from adherent leucocytes. ${ }^{1345}$ The reduction of caerulein induced pancreatic oedema by both L-arginine and SNP may therefore be a consequence of either or both of these mechanisms of NO action. It is paradoxical at first inspection that L-NAME also led to some reduction in oedema formation, but that effect may actually be due to a reduction in pancreatic perfusion, representing a worsening of the pancreatitis, as more severe forms of pancreatitis are characterised by a massive increase in inflammation with less pronounced oedema formation. ${ }^{2130}$

In this study pancreatic amylase secretion and intracellular trypsinogen activation in acinar cells were not altered by the addition of either NO donors or inhibitors in vitro, whether in resting, stimulated, or hyperstimulated cell preparations. Hyperstimulation of acini with caerulein can be considered a "cellular pancreatitis model", ${ }^{46}$ so that the absence of $\mathrm{NO}$ effects in vitro is further evidence that the alterations in amylase and TAP in vivo are secondary effects rather than primary effects on the acinar cell. These findings are consistent with the results of Molero et $a l,{ }^{25}$ who showed no alteration in basal and caerulein stimulated amylase release after the addition of L-NAME, and with those of Konturek and coworkers ${ }^{7}$ using $\mathrm{N}^{\mathrm{G}}$-nitro-Larginine, a different NO synthase inhibitor. However, Wrenn and coworkers ${ }^{47}$ reported that treatment of acini with L-arginine increased nitrite, cGMP, and amylase release, which were prevented by NO synthase inhibitors, and that $\mathrm{N}^{\mathrm{G}}$-nitro-L-arginine blocked carbachol induced amylase release. Whereas we used dispersed preparations of isolated acinar cells, Wrenn et al used cell clusters of 20-30 acinar cells, which are known to be more responsive to secretory stimulation. As neurones and microvascular endothelium may also have been included in those preparations, the effects of $\mathrm{NO}$ on pancreatic exocrine function in the study by Wrenn et al may be the result of paracrine rather than intracellular action. This hypothesis is supported by the observation that NO synthase activity, identified by immunohistochemical staining for nicotinamide adenine dinucleotide phosphate diaphorase, has been found in nerve fibres, nerve bodies, and the vascular endothelium, but not within the acinar cells in the pancreas of several mammalian species, including the rat and human. ${ }^{4}$

Our findings suggest that the primary effects of NO during acute pancreatitis seem to be via influences on pancreatic perfusion and on leucocyte-endothelium interaction. While reduced microcirculatory flow has been shown to be characteristic of severe pancreatitis, ${ }^{15}{ }^{16}$ it is possible that the increased numbers of leucocytes adhering to pancreatic endothelium and 
becoming activated at those sites precedes and leads to the perfusion deficits. This order of events is consistent with our finding of an increased presence of leucocytes even in mild caerulein induced pancreatitis in which capillary perfusion is still normal or even high. ${ }^{1640}$

Although NO and its action on leucocytes in pancreatitis appear to be beneficial under the conditions of this study, there may be a paradoxical dose-response phenomenon. Morikawa $e t$ al found that NO could either enhance or inhibit oxygen free radical generation in polymorphonuclear leucocytes at different concentrations, ${ }^{14}$ and high levels of NO produced by macrophages and lymphocytes can apparently cause tissue damage. ${ }^{6}$ These observations may explain how NO donors rather than $\mathrm{NO}$ inhibitors could make pancreatitis worse $\mathrm{e}^{22}$ or how cytotoxicity from NO may participate in the lung injury associated with pancreatitis. ${ }^{36}$

In summary, the present study reconfirms that $\mathrm{NO}$ has a positive beneficial effect in acute oedematous pancreatitis and indicates that this action is mediated by: (1) reduction in leucocyte adhesion and subsequent tissue infiltration; and (2) modulation of pancreatic microcirculation and tissue oxygenation. Direct effects of $\mathrm{NO}$ on pancreatic acinar cells, including regulation of pancreatic secretion, are likely to play only a minor role in the pathogenesis of this protective mechanism.

Jens Werner is supported by the Deutsche Forschungsgemein schaft, grant We2008/1-1 and 1-2.

1 Palmer RMJ, Ashton DS, Moncada S. Vascular endothelial cells synthesize nitric oxide from L-arginine. Nature 1988;333:664-6.

2 Hibbs JB, Taintor RR, Vavrin Z, et al. Nitric oxide: a cytotoxic activated macrophage effector molecule. Biochem Biophys Res Commun 1988;157:87-94.

3 Radomski MW, Palmer RMJ, Moncada S. An L-arginine: nitric oxide pathway present in human platelets regulates nitric oxide pathway present in human platelets regulat

4 Shimosegawa T, Abe A, Satoh A, et al. NADPH-diaphorase activity in neurons of the mammalian pancreas: coexpression with vasoactive intestinal polypeptide. Gastroenterology 1993;105:999-1008.

5 Hootman SR, Williams JA. Stimulus-secretion coupling in the pancreas acinus. In: Johnson LR, ed. Physiology of the gastrointestinal tract. New York: Raven, 1987:1129-46.

6 Moncada S, Higgs A. The L-arginine-nitric oxide pathway. N Engl F Med 1993;329:2012.

7 Konturek SJ, Szlachcic A, Dembinski A, et al. Nitric oxide in pancreatic secretion and hormone-induced pancreatitis in rats. Int $\mathcal{F}$ Pancreatol 1994;15:19-28.

8 Konturek SJ, Bilski J, Konturek PK, et al. Role of endogenous nitric oxide in the control of canine pancreatic secretion and blood flow. Gastroenterology 1993;104:896902 .

9 Waldmann SA, Murad F. Biochemical mechanisms underlying vascular smooth muscle relaxation: the guanylate ing vascular smooth muscle relaxation: the guanylate 12:115-18.

10 Ignarro LJ, Buga GM, Wood KS, et al. Endothelium-derived relaxing factor produced and released from artery and vein is nitric oxide. Proc Natl Acad Sci USA 1987;84:9265-9.

11 Radomski MW, Palmer R, Moncada S. Endogenous nitric oxide inhibits human platelet adhesion to vascular endothelium. Lancet 1987;ii:1057-8.

12 Kubes P, Suzuki M, Granger DN. Nitric oxide: an endogenous modulator of leucocyte adhesion. Proc Nat Acad Sci USA 1991;88:4651-5.

13 Gaboury J, Woodman RC, Granger N, et al. Nitric oxide prevents white blood cell adherence: role of superoxide and mast cells. Am F Physiol 1993;265:H862-7.

14 Morikawa M, Inoue M, Tokumaru S, et al. Enhancing and inhibitory effects of nitric oxide on superoxide anion generation in human polymorphonuclear leucocytes. Br $\mathcal{F}$ Pharmacol 1995;115:1302-6.

15 Klar E, Messmer K, Warshaw AL, et al. Pancreatic ischemia in experimental acute pancreatitis: mechanisms, significance, and therapy. Br f Surg 1990;77:1205-10

16 Knoefel WT, Kollias N, Warshaw AL, et al. Pancreatic microcirculatory changes in experimental pancreatitis of graded severity in the rat. Surgery 1994;116:904-13.
17 Werner J, Schmidt J, Langer C, et al. Leucocyteendothelium interaction correlates to the severity of acute pancreatitis. Pancreas 1995;11:452.

18 Rinderknecht H. Fatal pancreatitis, a consequence of excessive leucocyte stimulation? Int f Pancreatol 1988;3:105-12.

9 Gudgeon AM, Heath DI, Hurley P, et al. Trypsinogen activation peptides assay in the early prediction of severity of acute pancreatitis. Lancet 1990;335:4-8.

20 Fernandez-del Castillo C, Schmidt J, Warshaw AL, et al. Interstitial protease activation is the central event in progression to necrotizing pancreatitis. Surgery 1994;116: 497-504.

21 Werner J, Rivera J, Fernandez-del Castillo C, et al. Differing roles of nitric oxide in the pathogenesis of acute edematous versus necrotizing pancreatitis. Surgery 1997;121:23-30.

22 Abe T, Shimosegawa T, Satoh A, et al. Nitric oxide modulates pancreatic edema formation in rat caeruleinmodulates pancreatic edema formation in rat caerule

23 Toyama MT, Kusske AM, Reber PU, et al. Administration of a nitric oxide donor decreases the severity of acute pancreatitis [abstract]. Pancreas 1995;11:A451

24 Lampel M, Kern HF. Acute interstitial pancreatitis in the rat nduced by excessive doses of a pancreatic secretagogue. Virchows Arch A 1977;373:97-117.

25 Molero X, Guarner F, Salas A, et al. Nitric oxide modulates pancreatic basal secretion and response to cerulein in the rat: effects in acute pancreatitis. Gastroenterology 1995;108: 1855-62.

26 Menozzi D, Sato S, Jensen RT, et al. Cyclic GMP does not inhibit protein kinase C-mediated enzyme secretion in rat pancreatic acini. F Biol Chem 1989;264:995-9.

27 Knoefel WT, Kollias N, Rattner DW, et al. Reflectance spectroscopy of pancreatic microcirculation. $\mathcal{f}$ Appl Physiol 996;80:116-23.

28 Klebanoff SJ, Waltersdorph AM, Rosen H. Antimicrobial activity of myeloperoxidase. Methods Enzymol 1984;105: 399-403

29 Bradley PP, Priebat DA. Measurement of cutaneous inflammation. Estimation of neutrophil content with an enzyme marker. F Invest Dermatol 1982;78:206-9.

30 Werner J, Dragotakes SC, Fernandez-del Castillo C, et al. Technetium-99m-labeled white blood cells: a new method to define the local and systemic role of leucocytes in acute experimental pancreatitis. Ann Surg 1998;227:105-11.

31 Schmidt J, Lewandrowski K, Warshaw AL, et al. Morphometric characteristics and homogeneity of a new model of acute pancreatitis in the rat. Int $\mathcal{F}$ Pancreatol 1992;12:4151.

32 Schmidt J, Fernandez-del Castillo C, Rattner DW, et al. Trypsinogen activation peptides in experimental rat pancreatitis: prognostic implications and histopathologic

33 Ceska M, Birath K, Brown B. A new and rapid method for the clinical determination of alpha-amylase activities in human serum and urine. Clin Chim Acta 1969;26:437-44.

34 Bruzzone R, Halban PA, Gjinovci A, et al. A new, rapid method for preparation of dispersed pancreatic acini. Biochem f 1985;226:621-4.

35 Liu X, Nakano I, Yamaguchi H, et al. Protective effect of nitric oxide on development of acute pancreatitis in rats. Dig Dis Sci 1995;40:2162-9.

36 Tsukahara Y, Horita Y, Anan K, et al. Role of nitric oxide derived from alveolar macrophages in the early phase of acute pancreatitis. I Surg Res 1996;66:43-50.

37 Dabrowski A, Gabryelewicz A. Nitric oxide contributes to multiorgan oxidative stress in acute experimental pancreamultiorgan oxidative stress in acute experime

38 Whittle BJ, Lopez-Belmonte J, Moncada S. Regulation of gastric mucosal integrity by endogenous nitric oxide: interactions with prostanoids and sensory neuropeptides in the rat. Br F Pharmacol 1990;99:607-11

39 Nanji AA, Greenberg SS, Tahan SR, et al. Nitric oxide production in experimental alcoholic liver disease in the rat: role in protection from injury. Gastroenterology 1995;109: 899-907.

40 Satoh A, Shimosegawa T, Abe T, et al. Role of nitric oxide in the pancreatic blood flow response to caerulein. Pancreas 1994;9:574-9.

41 Kusterer K, Poschmann T, Friedemann A, et al. Arterial constriction, ischemia-reperfusion, and leucocyte adherence in acute pancreatitis. Am f Physiol 1993;265:6165-71.

42 Norman JG, Fink G, Franz M, et al. Active interleukin-1 receptor required for maximal progression of acute pancreatitis. Ann Surg 1996;223:163-9.

43 Schoenberg MH, Buechler M, Gaspar M, et al. Oxygen free radicals in acute pancreatitis of the rat. Gut 1990;31:113843

44 Clancy RM, Leszczynska-Piziak J, Abramson SB. Nitric oxide, an endothelial cell relaxation factor, inhibits neutrophil superoxide anion production via a direct action on the NADPH oxidase. 7 Clin Invest 1992;90:1116-21.

45 Hutcheson IR, Whittle BJR, Boughton-Smith NK. Role of nitric oxide in maintaining vascular integrity in endotoxininduced acute intestinal damage in the rat. Br $\mathcal{F}$ Pharmacol 1990;101:815-20.

46 Leach SD, Modlin IM, Scheele GA, et al. Intracellular activation of digestive zymogens in rat pancreatic acini. Stimulation by high doses of cholecystokinin. $\mathcal{F}$ Clin Invest 1991; 87:362-6.

47 Wrenn RW, Currie MG, Herman LE. Nitric oxide participates in the regulation of pancreatic acinar cell secretion. Life Sci 1994;55:511-18. 